\title{
Changes in subjective symptoms and allergy state among medical students exposed to low-level formaldehyde 6 months after completion of a gross anatomy dissection course
}

\author{
Mihoko Mori • Michiko Hoshiko • Kunio Hara • \\ Tsuyoshi Saga · Kouichi Yamaki • Tatsuya Ishitake
}

Received: 3 December 2012/Accepted: 22 March 2013/Published online: 16 April 2013

(C) The Japanese Society for Hygiene 2013

\begin{abstract}
Objectives Our purpose was to clarify whether subjective symptoms of low-level formaldehyde (FA) exposure in medical students were transient or persistent and to investigate whether the allergy state changed as a result of exposure.

Methods We surveyed the prevalence of medical students' subjective symptoms and their allergy state before, during, and 6 months after completion of a gross anatomy dissection course by using two self-administrative questionnaires. Students completed the first survey at the end of the anatomy course to assess symptoms before and during the course. The second survey was completed 6 months after course completion.
\end{abstract}

M. Mori $(\bowtie) \cdot$ M. Hoshiko · T. Ishitake

Department of Environmental Medicine,

Kurume University School of Medicine,

67 Asahi-machi, Kurume, Fukuoka 830-0011, Japan

e-mail: mkano@med.kurume-u.ac.jp

M. Hoshiko

e-mail: hmichi@med.kurume-u.ac.jp

T. Ishitake

e-mail: tishitak@med.kurume-u.ac.jp

K. Hara

Faculty of Community Health Care, Teikyo Heisei University,

4-1 Uruido-minami, Ichihara, Chiba 290-0193, Japan

e-mail: kunio.hara@thu.ac.jp

T. Saga $\cdot$ K. Yamaki

Department of Anatomy,

Kurume University School of Medicine, 67 Asahi-machi,

Kurume, Fukuoka 830-0011, Japan

e-mail: saga@med.kurume-u.ac.jp

K. Yamaki

e-mail: ky0250@med.kurume-u.ac.jp
Results The prevalence of most subjective symptoms was lower 6 months after the course than during the course. The major symptoms experienced during the course were eye fatigue, runny nose, and dry eyes. The most common symptom 6 months after the course was eye fatigue. Four students continued to experience symptoms even after course completion. Three students developed symptoms only after course completion. Forty-eight students had allergies before the course began and the severity of the allergies did not change after the course. Additionally, the prevalence of most subjective symptoms 6 months after the course was lower than before the course. The patterns of subjective symptoms in the three periods differed between male and female students; the prevalence of most subjective symptoms tended to be higher in females.

Conclusions Subjective symptoms resulting from FA exposure during a gross anatomy course were transient and did not affect students' allergy states.

Keywords Low-level FA exposure - Gross anatomy dissection course $\cdot$ Subjective symptoms $\cdot$ Allergy $\cdot$ Six months after completion of the course

\section{Introduction}

In Japan, medical students and lecturers are exposed to high levels of formaldehyde (FA) during gross anatomy dissection courses. There are concerns that this gives rise to FA-related symptoms such as headache, fatigue, and irritation of the eyes, nose, and throat. Furthermore, FA exposure during dissection may induce specific IgE, but not $\mathrm{IgG}$, against FA-albumin [1]. Experiments on animals have demonstrated that low-level exposure to FA by inhalation has an impact on oxidant stress in a tissue-specific manner 
[2]. In addition, inhalation of FA has been shown to inhibit learning and memory performance in mice [3].

Many Japanese universities have assessed FA concentrations in gross anatomy laboratories [4-8], and as a result, have remodeled their laboratories to try to limit exposure during dissection classes. This had led to improvements in the FA concentration. For instance, Igarashi et al. [9] reported that FA concentrations in a dissection room decreased from 0.7 to $0.2 \mathrm{ppm}$ after the installation of an FA gas diminution system. Similarly, Kikuta et al. [10] reported a reduction of FA concentration in a gross anatomy laboratory from 1.39 to $0.04 \mathrm{ppm}$ under conditions of total ventilation and local ventilation. There have also been many reports of the effects of measures developed to reduce indoor FA concentrations [11-14].

In our university, we began taking measures to reduce FA exposure during dissection classes in 2006. We attempted to reduce the indoor levels of FA in a gross anatomy dissection room by stepped interventions, and we have continued to monitor indoor FA concentrations from 2006 to 2008. Furthermore, we have conducted surveys of users of the dissection laboratory. In the years in which the concentrations were measured, both the indoor FA concentrations and the FA exposure concentrations exceeded the values set out in the government guideline $(0.25 \mathrm{ppm})$ [15] on all measured days [16]. Thus, we continue with FA generation source control and individual FA exposure measurements. The implementation of these measures has significantly decreased indoor FA levels. However, the levels recorded failed to fall below $0.1 \mathrm{ppm}$ [17].

Finally, large-scale repair work was carried out between January and March 2011. This work involved the installation of all new dissection tables equipped with local ventilation systems and the renewal of the general ventilation system. After these improvements, the indoor concentrations of FA dropped by nearly $90 \%$ from the levels observed in 2008. Thus, by stepped intervention, we were able to reduce the indoor levels of FA. To assess the effects of our interventions, we conducted a questionnaire survey among the 2011 users of the room and compared the results with those obtained from surveys carried out before the large-scale repair work. After this large-scale repair work, the number of persons with subjective symptoms was significantly reduced; however, not all students' symptoms disappeared [18]. In addition, there have been few investigations of the health effects of low-level FA exposure in medical students and animals. Therefore, we believe there is a need to continue measuring indoor FA concentrations and devise further strategies to reduce FA exposure, even beyond that achieved by the measures already implemented. There are few studies in the literature that have examined and compared medical students' subjective symptoms and allergy states during and after gross anatomy dissection courses. Hisamitsu et al. investigated clinical symptoms immediately before, immediately after, and 6 months after completion of a systematic anatomy practice. Their study of 41 students found that clinical symptoms experienced during the course disappeared 6 months after course completion [19]. In addition, we previously found in 2006 that few students at our institution experienced symptoms and that their allergies were not exacerbated 6 months after course completion; this was before the large-scale repair work was carried out [16]. However, in our survey conducted during 2006, we did not inquire about the degree of concrete subjective symptoms that the students experienced. In addition, for our 2006 study, the indoor levels of FA were much higher than those after the large-scale repair work. Thus, in the present study, we surveyed the prevalence of subjective symptoms and the allergy states in students before, during, and 6 months after the end of a gross anatomy dissection course during which they had been exposed to low levels of FA. This prevalence was assessed by selfadministered questionnaires that were completed by all students immediately after and 6 months after completing the course. The purpose of this study was to clarify whether any subjective symptoms associated with low-level FA exposure were transient or persistent, and whether the allergy states of students were changed.

\section{Materials and methods}

\section{Study population}

The study population consisted of 121 university medical students at Kurume University's School of Medicine. All students participated in afternoon sessions of systematic anatomy practice from April to July 2011.

\section{Questionnaire}

We conducted two self-administered questionnaires. The first survey was conducted on the last day of the anatomy course in July 2011 to examine subjective symptoms and allergy states before and during the course. The second survey was administered in January 2012, 6 months after completion of the course; this survey examined subjective symptoms and allergy states in the previous month. The questions contained in the first and second questionnaires are shown in the Appendix. We defined an allergy as any allergy diagnosed by a doctor. The 24 subjective symptoms in the first questionnaire consisted of eye, nose, and throat complaints and indefinite complaints; the same symptoms were used in the second questionnaire. Possible responses to questions about the frequency of subjective symptoms were "never," "sometimes," and "often." 
Statistical analysis

Participants who answered that they "sometimes" or "often" experienced a subjective symptom were classified as having the subjective symptom. We calculated the number of people with each subjective symptom and labeled this category as the "prevalence of subjective symptoms." The prevalence of each subjective symptom before, during, and 6 months after the course was compared using McNemar's test. Similarly, we analyzed the prevalence of each subjective symptom before, during, and 6 months after the course according to gender. The prevalence of one or more subjective symptoms, the number of people with an allergy history, subjective symptoms after course completion, change in severity of allergy symptoms, and symptoms similar to sick building syndrome were statistically compared between male and female students by using the $\chi^{2}$ test. Differences in age were statistically compared between male and female students by using the $t$ test. Patterns of subjective symptoms were statistically compared between students with and without allergies by using the $\chi^{2}$ test. All statistical analyses were performed using IBM SPSS Statistics for Japan ver. 19. Statistical significance was two-tailed and set at $P<0.05$ for all analyses.

Ethical considerations and informed consent

This study was approved by the Ethical Committee of Kurume University. All participants were informed about the content and objectives of this study in written form.

\section{Results}

Sample

The collection rate for both questionnaires was $100 \%$, and we used all data for analysis. The demographic characteristics of respondents are shown in Table 1. Mean age at the first survey was 22.3 years ( $\mathrm{SD}, 3.0$ years). There was no significant difference in mean age between male and female students. A total of $75.2 \%$ of the subjects were male.

Subjective symptoms before, during, and 6 months after the course

The percentages of students with more than one subjective symptom before, during, and 6 months after the course were $81.0,86.8$, and $50.4 \%$, respectively (Table 1). The prevalence of one or more subjective symptoms was lowest 6 months after the course. Female students had a
Table 1 Demographic characteristics of respondents

\begin{tabular}{llll}
\hline & $n(\%)$ & & \\
\cline { 2 - 4 } & All & Male & Female \\
\hline $\begin{array}{l}\text { Age at first survey (years; } \\
\text { mean } \pm \text { SD) }\end{array}$ & $22.3 \pm 3.0$ & $22.5 \pm 2.7$ & $21.8 \pm 3.7$ \\
Sex & & & \\
Male & $91(75.2)$ & & \\
Female & $30(24.8)$ & & \\
One or more subjective symptom & & \\
Before course & $98(81.0)$ & $72(79.1)$ & $26(86.7)$ \\
During course & $105(86.8)$ & $76(83.5)$ & $29(96.7)$ \\
Six months after & $61(50.4)$ & $38(41.8)$ & $22(73.3)$ \\
$\quad$ completion of the & & & \\
$\quad$ course* & & & \\
People with allergy history & & & \\
Total & $48(39.7)$ & $38(41.8)$ & $10(33.3)$ \\
Hay fever & $28(23.1)$ & $21(23.1)$ & $7(23.3)$ \\
Allergic rhinitis & $23(19.0)$ & $19(20.9)$ & $4(13.3)$ \\
Alimentary allergy & $10(8.3)$ & $9(9.9)$ & $1(3.3)$ \\
Atopic dermatitis & $9(7.4)$ & $8(8.8)$ & $1(3.3)$ \\
Bronchial asthma & $6(5.0)$ & $5(5.5)$ & $1(3.3)$ \\
Allergic conjunctivitis & $3(2.5)$ & $2(2.2)$ & $1(3.3)$ \\
Hives & $2(1.7)$ & $1(1.1)$ & $1(3.3)$ \\
Other & $1(0.8)$ & $1(1.1)$ & $0(0.0)$ \\
\hline
\end{tabular}

* Significant difference between male and female $(P<0.05)$

significantly higher prevalence of one or more subjective symptoms 6 months after completion than male students. Figure 1 shows the changes in prevalence of the concrete subjective symptoms before, during, and 6 months after the course. The prevalence of 16 of the 24 symptoms was higher during the course than during the other two periods. The prevalence of most symptoms was lower 6 months after the course than either before or during the course. The prevalence of 21 of the 24 symptoms was significantly decreased 6 months after the course compared with during the course. In addition, the prevalence of 17 of the 24 symptoms was significantly decreased 6 months after the course compared with before the course.

Figures 2 and 3 show the changes in the prevalence of concrete subjective symptoms before, during, and 6 months after the course for male and female students, respectively. Among male students, the prevalence of 17 of the 24 symptoms was significantly decreased 6 months after the course compared with during the course. In contrast, among female students, the prevalence of five of the 24 symptoms was significantly decreased 6 months after the course compared with during the course. Overall, the prevalence of most subjective symptoms tended to be higher in female than in male students during all periods. 


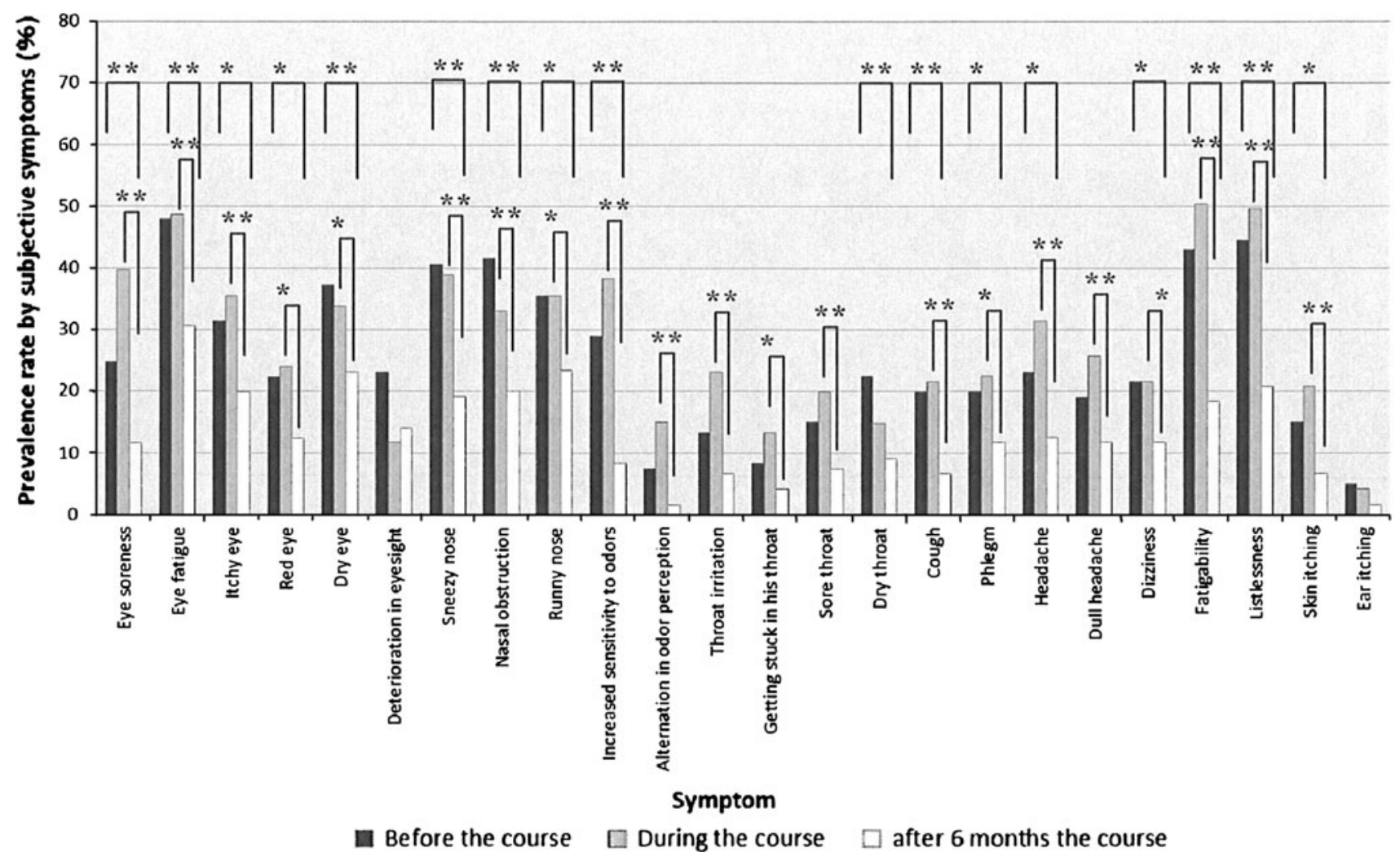

Fig. 1 Changes in prevalence of subjective symptoms before, during, and 6 months after gross anatomy dissection course. *Significant difference between prevalence before or during the course and

\section{Continuing existence of subjective symptoms}

Table 2 shows the continuing existence of subjective symptoms after completion of the course. Four students continued to experience subjective symptoms. Three of the four students reported each of the following subjective symptoms: deterioration in eyesight, dry eye, and itchy eye. Thus, all symptoms were eye-related. Three students developed such symptoms immediately after completion of the course. Two students developed a runny nose and nasal congestion, and one student developed conjunctivitis immediately after the course. Most students answered that the severity of symptoms 6 months after the course was the same or lower than that during the course (data not shown). There were differences in the continuing existence of subjective symptoms after course completion between male and female students.

\section{Status of allergy symptoms}

The status of allergy symptoms is shown in Table 1 . There were 48 students $(39.7 \%)$ with an allergy history. This included 28 students $(23.1 \%)$ with hay fever and 23 students $(19.0 \%)$ with allergic rhinitis. There were no
6 months after the course $(P<0.05)$. **Significant difference between prevalence before or during the course and 6 months after the course $(P<0.01)$

differences in the category of allergies between male and female students. All students with an allergy answered that allergy onset occurred before the start of the course (Table 2). Five students experienced a worsening of allergy status during the course, while another five students reported a worsening before the course. The severity of the allergies of the remaining 38 students did not change (Table 2). There was no significant difference between male and female students in terms of changes in severity of allergy symptoms.

Change in patterns of subjective symptoms according to existing allergy

We compared changes in the patterns of subjective symptoms between students with an allergy and those without allergies. No change in the pattern of any subjective symptoms was observed in either group.

Symptoms similar to sick building syndrome

Twenty-seven students $(22.3 \%)$ answered that they often or sometimes felt uncomfortable when entering new residential housing places or detecting the smell of cigarettes 


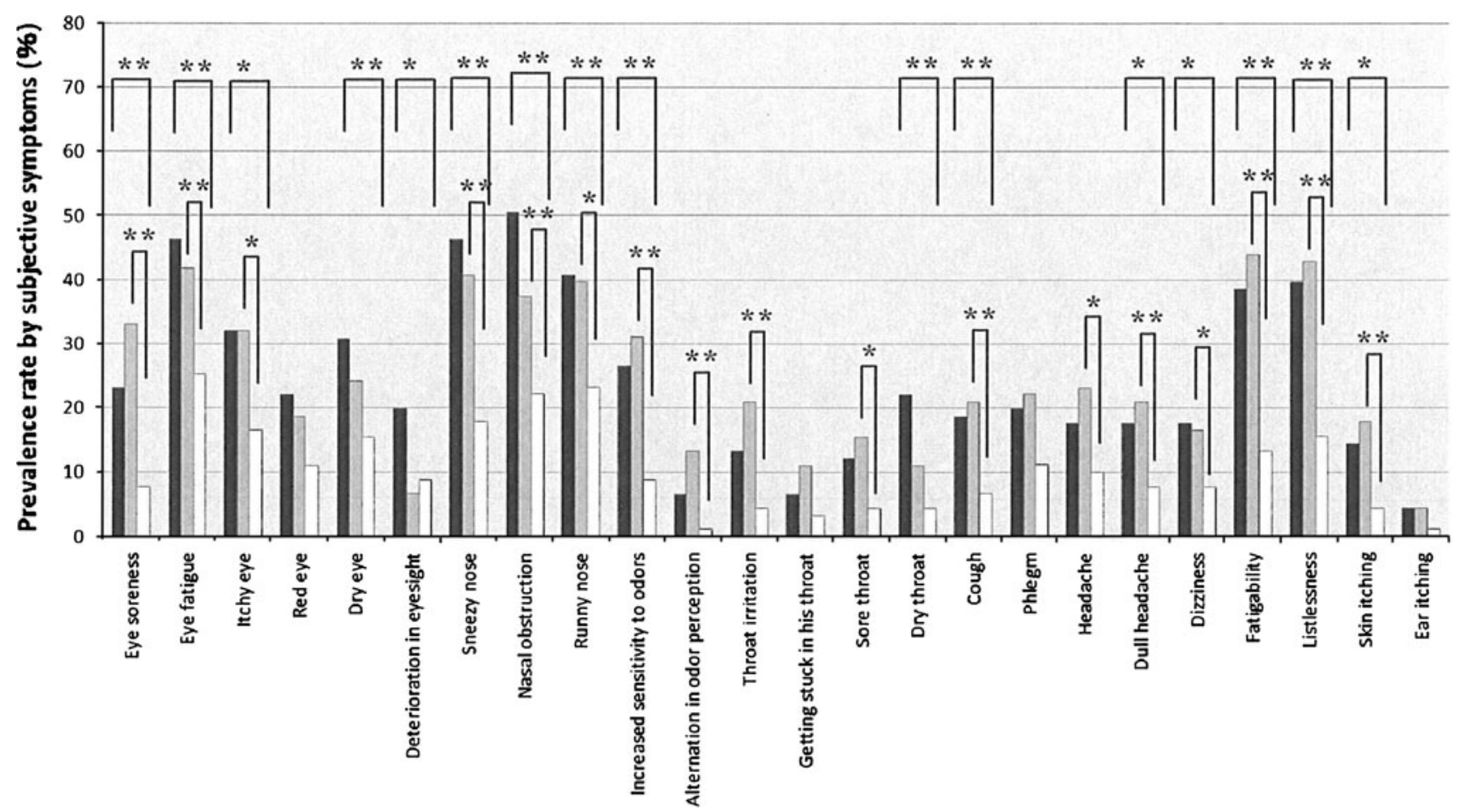

Symptom

Before the course $\square$ During the course $\square$ after 6 months the course

Fig. 2 Changes in prevalence of subjective symptoms before, during, and 6 months after gross anatomy dissection course (male students). *Significant difference between prevalence before or during the

(Table 2). One student in our study answered that he first began to have this sensation after the course. This student did not have an allergic history. There were no differences between male and female students in the reported rates of symptoms similar to those of sick building syndrome.

\section{Discussion}

In the present study, we surveyed the prevalence of subjective symptoms of students who undertook a gross anatomy dissection course under conditions of low-level indoor FA after large-scale repair work at our university. The prevalence of many subjective symptoms increased during the course compared with before the course; however, the prevalence of many symptoms had decreased by 6 months after the course. Additionally, no students experienced a worsening of allergy symptoms 6 months after the course. In the present study, subjective symptoms continued in only four students up to 6 months after the course. One student experienced a worsening of severe symptoms (deterioration in eyesight) 6 months after the course. All other students responded that their current symptoms were at the same or a lower level than those course and 6 months after the course $(P<0.05)$. **Significant difference between prevalence before or during the course and 6 months after the course $(P<0.01)$

experienced during the course. Notably, no student thought that the continuation of symptoms 6 months after the course could be attributed to the anatomy practice. From these results, we suggest that the subjective symptoms that occur due to FA exposure during a gross anatomy dissection course are transient.

In this survey, we showed that there were differences between male and female students in terms of the patterns of subjective symptoms within the three periods. The prevalence of most subjective symptoms tended to be higher in female than in male students. Tanaka et al. [8] also found that female subjects reported more FA-related subjective symptoms than male subjects. Sick building syndrome and multiple chemical sensitivity patients are common among females in Japan, and the present results agree with these findings [20, 21].

The changes in FA-related subjective symptoms and allergy states have been investigated in several previous studies. In 2006, we conducted a follow-up survey analyzing subjective symptoms and allergy states in medical students after FA exposure. In that study, we found that most students' symptoms had disappeared by 6 months after course completion and that their allergy states had improved [16]. Importantly, the mean FA concentration in 


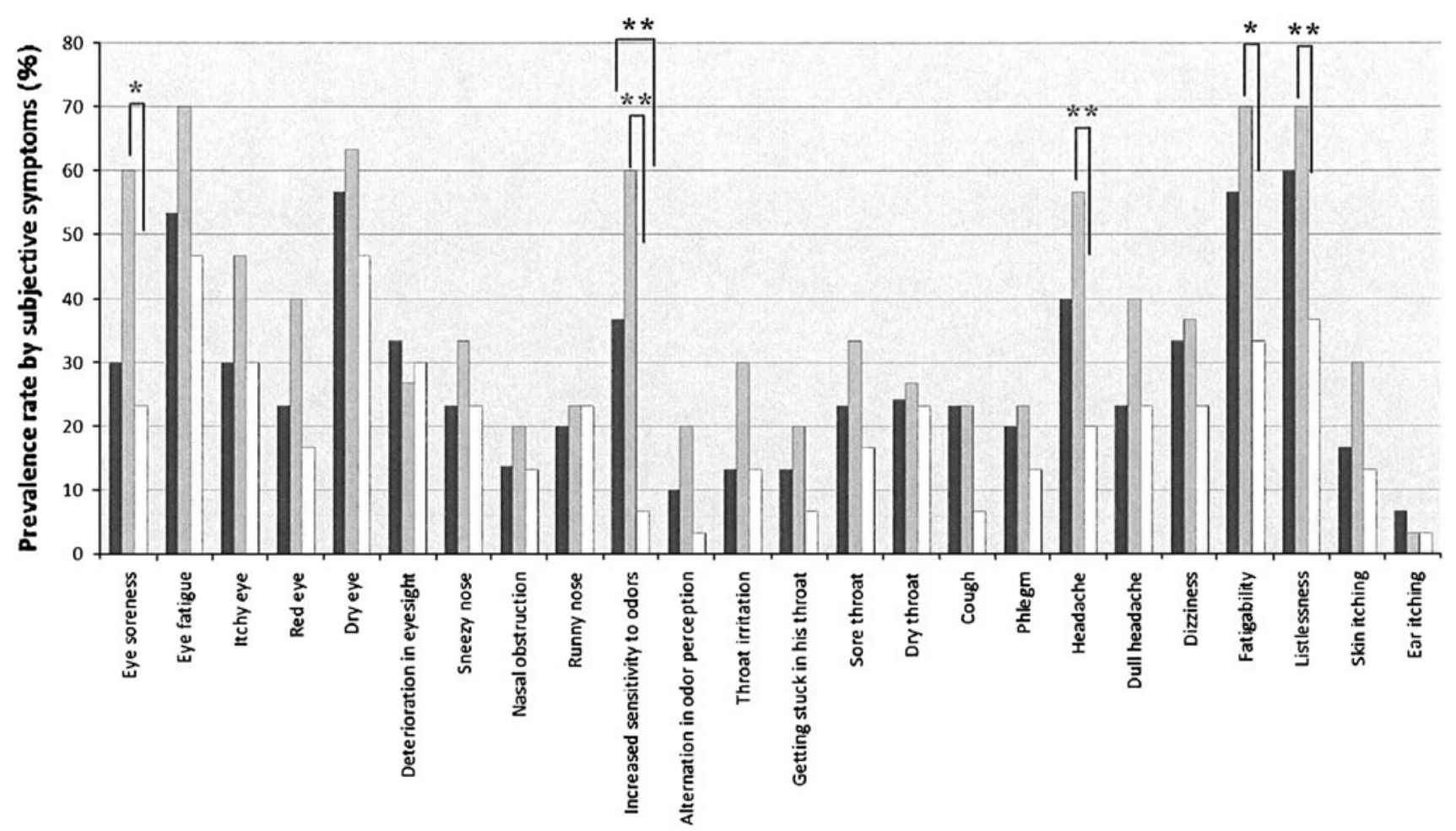

Symptom

Before the course $\square$ During the course $\square$ after 6 months the course

Fig. 3 Changes in prevalence of subjective symptoms before, during, and 6 months after gross anatomy dissection course (female students). *Significant difference between prevalence before or during the

the dissection room during the 2006 course was approximately eight times higher than the concentration in this study, because that study was conducted before the major repair work was carried out. Despite the higher FA concentrations present in our earlier study, we found that the prevalence of subjective symptoms was either greatly reduced or partly reduced by 6 months after the course compared with before and during the course. However, the questionnaires used in the 2006 study and those used in this study had key differences. In 2006, participants were asked about the presence of any continuing subjective symptoms 6 months after course completion.In 2011, we inquired about the presence of each continuing concrete subjective symptom 6 months after course completion. Therefore, we were able to determine the changes in students' subjective symptoms in greater detail in the present study.

Hisamitsu et al. [19] also studied changes in subjective symptoms and allergy states during a gross anatomy dissection course. They serially measured serum IgE levels and nasal mucosal sensitivity to histamine, and they conducted olfactory tests in medical students immediately before and after the course and then again at 6 months after completion of the course. They observed temporary abnormalities in olfactory test results and increased nasal course and 6 months after the course $(P<0.05)$. **Significant difference between prevalence before or during the course and 6 months after the course $(P<0.01)$

mucosal hypersensitivity to histamine after environmental exposure to high concentrations of FA in several students with preexisting allergic rhinitis. However, the symptoms disappeared in all subjects studied upon completion of the course. FA concentrations in the center of the anatomy laboratory in that study ranged from 0.51 to $0.97 \mathrm{ppm}$. These FA concentrations therefore reduced between the concentrations noted in our laboratory in 2006 and those noted in 2011 [17]. The results of Hisamitsu et al. are consistent with our results to the extent that subjective symptoms disappeared 6 month after the course.

The present study has two possible limitations. The first is that the students answered questions on their pre-course allergy and symptom status when they had already completed the course. Therefore, there is the possibility of recall bias.Alternatively, answering questions on precourse symptoms at the same time as answering questions on symptoms experienced during the course may allow students to more directly compare pre- and post-course symptoms and therefore clarify the effects of the course on their symptoms.

The interpretation of these results is also limited by the possible confounding factor of the seasons during which the symptoms were reported. We conducted the surveys for 
Table 2 Status of subjective symptoms and allergy symptoms

\begin{tabular}{|c|c|c|c|}
\hline & \multicolumn{3}{|l|}{$n(\%)$} \\
\hline & All & Male & Female \\
\hline \multicolumn{4}{|l|}{$\begin{array}{l}\text { Subjective symptoms after } \\
\text { course completion* }\end{array}$} \\
\hline Continuing & $4(3.3)$ & $3(3.3)$ & $1(3.3)$ \\
\hline $\begin{array}{l}\text { Developed immediately } \\
\text { after course }\end{array}$ & $3(2.5)$ & $2(2.2)$ & $1(3.3)$ \\
\hline $\begin{array}{l}\text { Disappearance of symptoms } \\
\text { after course }\end{array}$ & $40(33.1)$ & $23(25.3)$ & $17(56.7)$ \\
\hline No symptoms & $74(61.2)$ & $63(69.2)$ & $11(36.7)$ \\
\hline \multicolumn{4}{|l|}{$\begin{array}{l}\text { Change in severity of allergy } \\
\text { symptoms }\end{array}$} \\
\hline Worse during course & $5(10.4)$ & $4(10.5)$ & $1(10.0)$ \\
\hline Worse before course & $5(10.4)$ & $4(10.5)$ & $1(10.0)$ \\
\hline No change & $38(79.2)$ & $30(79.0)$ & $8(80.0)$ \\
\hline \multicolumn{4}{|l|}{ Allergy onset } \\
\hline Before start of course & $48(100.0)$ & $38(100.0)$ & $10(100.0)$ \\
\hline \multicolumn{4}{|l|}{$\begin{array}{l}\text { Symptoms similar to sick } \\
\text { building syndrome }\end{array}$} \\
\hline Often & $5(4.1)$ & $4(4.4)$ & $1(3.3)$ \\
\hline Sometimes & $22(18.2)$ & $15(16.7)$ & $7(23.3)$ \\
\hline Never & $94(77.7)$ & $72(78.9)$ & $23(73.4)$ \\
\hline
\end{tabular}

* Significant difference between male and female $(P<0.05)$

symptoms experienced before (March), during (from April to July), and 6 months after (January) a gross anatomy dissection course. These periods are associated with varying amounts of environmental pollen and different allergy status characteristics. Therefore, our results might be influenced, to some degree, by the timing of the surveys.

FA exposure during anatomy courses should be prevented as it may act as a trigger for the development of sick building syndrome or chemical sensitivity. Many reports have focused on FA exposure-induced sick building syndrome in new residential housing [22]. In the present survey, $22.3 \%$ of participants said that they had experienced an uncomfortable feeling when entering a new residential housing place or detecting the smell of cigarettes. One participant experienced this uncomfortable feeling for the first time after taking the gross anatomy dissection course. Therefore, this student's health status should be followed up to determine the possible effects of these sensations on daily life.

Figure 4 shows the mean indoor FA concentrations over a $20 \mathrm{~min}$ period, starting $30 \mathrm{~min}$ after the beginning of the practice in 2011. The mean concentration $( \pm$ SD) of FA at the center of our laboratory was $0.14 \pm 0.05 \mathrm{ppm}$ [18]. Importantly, on some days, the concentration was above the government-set FA limit [23]. On the basis of our past results, we propose the implementation of comprehensive measures to reduce FA exposure. These include increasing

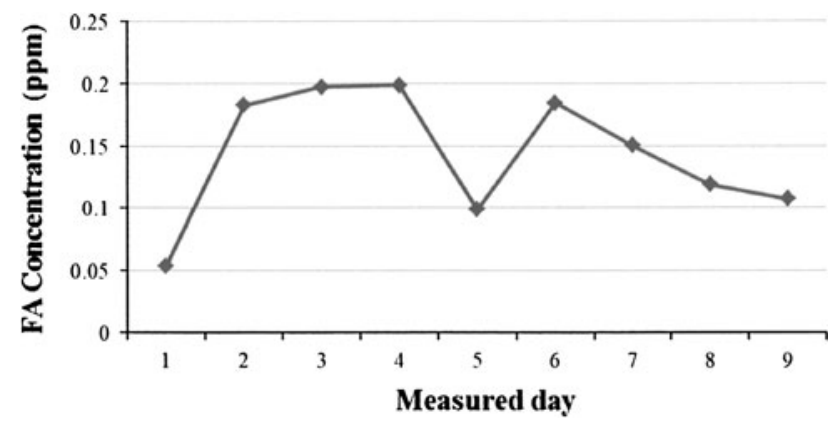

Fig. 4 Indoor concentrations of FA 30 min after the practice began (figure excerpted partly from Fig. 1 in Ref. [18]). "Measured day" in the horizontal axis means the day when the indoor FA concentration was measured, on every Monday from May to July

the ventilation air volume when FA concentrations rise during procedures such as thoracotomy and laparotomy. Students also need to be informed about the possibility that FA concentrations may increase. In addition, the importance of wearing protective equipment and reducing consecutive working hours (including changes to rest and practice times) needs to be stressed to students. Future efforts should focus on the careful maintenance of ventilation systems, the measurement of indoor FA levels, continued safety education for students, and attempts to further minimize students' exposure to FA.

Acknowledgments The authors thank the university medical students at Kurume University School of Medicine who participated in this study and the lecturers of the Department of Anatomy, Kurume University School of Medicine, who cooperated with our study.

Conflict of interest The authors declare that they have no conflicts of interest.

\section{Appendix}

Question items administered on the last day of the anatomy course and 6 months after completion of the course.

Last day of the anatomy course 6 months after completion of the course

1. How often did you experience 1 How often did you experience each subjective symptom before the course? (24 each subjective symptom in the last month? (24 symptoms)* symptoms)*

2 How often did you experience 2 Do you have remaining each subjective symptom during the course? (24 subjective symptoms after the completion of the course? symptoms)*

3 Do you have any allergies that 3 What symptoms are remaining were diagnosed by a doctor? now? 
Appendix continued

Last day of the anatomy course 6 months after completion of the course

4 What allergies do you have? 4 Do you think that the symptoms developed because of taking the course?

5 When did you develop the allergies?

5 How severe are the symptoms you have?

6 How did you change in allergy severity?

6 Have you experienced allergy symptoms in the last month? (24 symptoms)

7 Did you wear personal protective equipment during the course?

7 How did you change in allergy severity?
8 Why did you not wear personal protective equipment?

8 Do you have any symptoms similar to sick building syndrome?

9 Have you had these symptoms similar to sick building syndrome since before the practice?

* The subjective symptoms provided for questions 1 and 2 on the last day of the anatomy course and for question 1 at 6 months after completion of the course were the same

\section{References}

1. Wantke F, Focke M, Hemmer W, Bracun R, Wolf-Abdolvahab S, Gotz M, Jarisch R. Exposure to formaldehyde and phenol during an anatomy dissecting course: sensitizing potency of formaldehyde in medical students. Allergy. 2000;55:84-7.

2. Matsuoka T, Takaki A, Ohtaki H, Shioda S. Early changes to oxidative stress levels following exposure to formaldehyde in ICR mice. J Toxicol Sci. 2010;35:721-30.

3. Lu Z, Li CM, Qiao Y, Yan Y, Yang X. Effect of inhaled formaldehyde on learning and memory of mice. Indoor Air. 2008; 18:77-83

4. Kunugita N, Nakashima T, Kikuta A, Kawamoto T, Arashidani $\mathrm{K}$. Exposure to formaldehyde during an anatomy dissecting course. J UOEH. 2004;26:337-48 (in Japanese).

5. Mizuki M, Tsuda T. Relationship between atopic factors and physical symptoms induced by gaseous formaldehyde exposure during an anatomy dissection course. Arerugi. 2001;50:21-8 (in Japanese).

6. Ohmichi K, Matsuno Y, Komiyama M, Fukuda H, Todaka E, Ohta $\mathrm{M}$, et al. Study of formaldehyde concentration during gross anatomy laboratory in Chiba University. Jpn J Clin Ecol. 2005;14:112-8 (in Japanese).

7. Takayanagi M, Sakai M, Ishikawa Y, Murakami K, Kimura A, Kakuta S, et al. Formaldehyde concentrations in the breathing zone of medical students during gross anatomy laboratory in Toho University. Kaibogaku Zasshi. 2007;82:45-51 (in Japanese)

8. Tanaka K, Nishiyama K, Yaginuma H, Sasaki A, Maeda T, Kaneko S, et al. Formaldehyde exposure levels and exposure

control measures during and anatomy dissecting course. Kaibogaku Zasshi. 2003;78:43-51 (in Japanese).

9. Igarashi Y, Satake T, Sasaki K, Matsuno M, Nakayama M, Sakurai S, et al. Improvement of the condition of the air in the dissection room at Nihon University School of Dentistry at Matsudo. Nihon Univ J. 2007;33:73-80 (in Japanese).

10. Kikuta A, Yamato H, Knunugita N, Nakashima T, Hayashi H. Reducing the levels of formaldehyde exposure during a gross anatomy dissection course with a local ventilation system. Kaibogaku Zasshi. 2010;85:17-27 (in Japanese).

11. Matsuda S, Hasegawa M, Muro H, Asano H, Hamada F, Shimokawa $\mathrm{T}$, et al. The effects of a novel local ventilation system to reduce the health hazard to students during gross anatomy courses. Kaibogaku Zasshi. 2009;84:103-9 (in Japanese).

12. Shinoda K, Oba J. Formaldehyde-reducing efficiency of a newly developed dissection-table-connected local ventilation system in the gross anatomy laboratory room. Kaibogaku Zasshi. 2010;85:5-15 (in Japanese).

13. Takayanagi M, Sakai M, Ishikawa Y, Murakami K, Kimura A, Kakuta S, et al. Attempt to reduce the formaldehyde concentration by blowing cooled fresh air down into the breathing zone of medical students from an admission port on the ceiling during gross anatomy class. Kaibogaku Zasshi. 2008;83:87-93 (in Japanese).

14. Yamato H, Nakashima T, Kikuta A, Kunugita N, Arashidani K, Nagafuchi $\mathrm{Y}$, et al. A novel local ventilation system to reduce the levels of formaldehyde exposure during a gross anatomy dissection course and its evaluation using real-time monitoring. J Occup Health. 2005;47:450-3.

15. Japanese Ministry of Health, Labour and Welfare. Guidelines for reducing formaldehyde concentrations in indoor air of workplaces. Tokyo. http://www.mhlw.go.jp/houdou/2002/03/h03154.html/.

16. Mori M, Hara K, Ishitake T, Saga T, Yamaki K. Research on indoor levels of formaldehyde and subjective symptoms in medical students during a gross anatomy dissection course. Jpn $\mathrm{J}$ Clin Ecol. 2008;17:13-20 (in Japanese).

17. Mori M, Hoshiko M, Hara K, Ishitake T, Saga T, Yamaki K. Reduction in indoor levels of formaldehyde in a gross anatomy dissection room by gradual intervention. Jpn J Clin Ecol. 2011;20:123-30 (in Japanese).

18. Mori M, Hoshiko M, Hara K, Ishitake T, Saga T, Yamaki K. Effect of large-scale repair work on indoor formaldehyde levels and subjective symptoms in medical students during a gross anatomy dissection course. Jpn J Hyg. 2012;67:501-7 (in Japanese).

19. Hisamitsu M, Okamoto Y, Chazono H, Yonekura S, Sakurai D, Horiguchi S, et al. The influence of environmental exposure to formaldehyde in nasal mucosa of medical students during cadaver dissection. Allergol Int. 2011;60:373-9.

20. Hojo S, Ishikawa S, Kumano H, Miyata M, Matsui T, Sakabe K. Subjective and objective characteristics of patients with multiple chemical sensitivity in Japan. Jpn J Clin Ecol. 2007;16:104-16 (in Japanese).

21. Hasegawa K. Clinical aspects of sick-house syndrome and multiple chemical sensitivity. IRYO. 2009;63:11-7 (in Japanese).

22. Ogawa M, Nishinakagawa S, Yokosawa F, Goto H, Kawamoto T, Endo Y. A case of sick house syndrome in which the main symptom was allergy to formaldehyde. San Ei Shi. 2008;50:83-5 (in Japanese).

23. The Japan Society for Occupational Health. Recommendation of occupational exposure limits (2011-2012). J Occup Health. 2011;53:395-411. 